\title{
Hapticity in Digital Education Atmosphere
}

\author{
Esen Gokce Ozdamar \\ Department of Architecture, Tekirdă̆ Namık Kemal University (TNKU), Tekirdag, Turkey \\ Gokcen Firdevs Yucel Caymaz \\ Department of Architecture, Istanbul Aydin University (IAU), Istanbul, Turkey \\ Hulya Yavas \\ Department of Architecture, Istanbul Aydin University (IAU), Istanbul, Turkey
}

Received: August 17th 2021, Revised: October 13rd 2021, Accepted: October 21st 2021.

Refer: Ozdamar, E.G., Yucel Caymaz, G.F., Yavas, H., (2021), Hapticity in Digital Education Atmosphere, Journal of Design Studio, V.3, N.2, pp 141-157,

E. G. Ozdamar ORCID: 0000-0001-7189-3633, G. F. Yucel Caymaz ORCID: 0000-0002-0012-8384, H. Yavas ORCID: 0000-0002-81532118

DOI: $10.46474 /$ jds.982811 https://doi.org/10.46474/jds.982811

\begin{abstract}
This article focuses on the effects of the decreased ability to perceive touch in distance learning for all of the actors in architectural design studios during the ongoing Covid-19 pandemic. As part of face-to-face architectural pedagogy, the tactile experience of architectural materials, models, and corporeality in the studio environment assumes great importance. However, in contrast, these aspects are diminished when it comes to digital education, generating new topics for discussion. This article asks how and to what extent distance education models can affect the process of learning, understanding, discussing, and designing architecture, amidst the prospect of continuous digital education in the post-pandemic period. Hence, it examines the awareness and experiences of haptic perception of first-year students at the Istanbul Aydın University Department of Architecture through in-depth interviews recorded on Zoom. Between 2020 and 2021, the interviews investigated haptic perception, observed construction techniques, factors affecting design materials, the way and place in which materials were perceived, the methods of sharing and transferring designs with studio instructors, questions about the obstacles encountered, and expectations for the post-pandemic period. The outcomes of these in-depth interviews showed that there is a close relationship between the students' bodily interests and their awareness with regards to perceiving materials and that the former indicated a tendency towards making models. It was observed that students had preferred digital design tools in the pre-pandemic period, and in addition to the digital tools that students often use as a design approach, they negotiated as designing through hand-drawing in order to gain the "thinking with one's hands" experience in this study. This emphasizes the need for haptic experiences in an architectural educational environment.
\end{abstract}

Keywords: Architectural design studio environment, digital environment, distance learning, haptic learning in distance education, multi-modal perception, material perception.

\section{Introduction}

Following the outbreak of the Covid-19 pandemic, one of the difficulties of distance learning in architecture is the issues caused by the decreased interdisciplinary interaction and dialogue between instructors and their students. As Salama and Crosbie mention (2020) some of the emerging challenges and online restrictions that the students may face include "access to software from off-campus sites along with high-speed broadband or specialist computers for modeling and visualization". Indeed, the most common disadvantages when compared with face-toface learning are the communication problems faced by students, which may cause the instructors to "use multiple applications" (Ibrahim, Attia, Bataineh, and Ali, 2020, p. 1). 
Other restrictions and challenges faced by the students and instructors who live in nonuniversity households include experiencing power outages during the pedagogical process, lacking access to architectural models and materials (which often corresponds to the remote location of their residences), and the decrease in hapticity as part of a distance - the focus of this article. Other challenges that may arise are the restrictions or suppressive factors such as personal worries or self-censorship in some politically-related architectural discussions, and consequently, the students' concerns that they may be faced by both the instructors and students in different contexts due to the recording and inspection of the courses.

In contrast to all of these challenges, there are some advantages to distance learning, such as "openness, flexibility, volume, and accessibility" with regard to "open educational tools and courses, educational methods or management approach educational services, and time" and the fact that it "does not contend with the restrictions of time, place and educational tools" (Ibrahim, Attia, Bataineh, and Ali, 2020, p. 1). In addition, it is significant that the lessons can be viewed and downloaded again-allowing students to watch the lesson at an accelerated or sloweddown speed-depending on their perception and speed-and to gain transparent and openaccess opportunities.

In addition to these challenges and advantages, another important issue is the relatively limited effect of student-instructor interactions and the production practices of architectural design studios that are realized collectively. At this point, some potential fundamental problems with the students' perceptive abilities may arise. The fact that a digital screen does not activate our haptic sense, or appears invisible in contrast to more easily perceivable visual layers - such as images, sound, and motionappears to be an important problem. What kind of possible problems can arise out of the simultaneous co-existence of all the senses in digital architectural studio environments? In distance learning, it is observed that haptic skills and the experiences of the students in learning and comprehending design are restricted.

Based on both the decreased and restricted haptic practices and experiences of design and architecture that students have undergone through distance learning during the Covid-19 pandemic in Turkey, this article addresses how a gradually decreasing haptic experience can shape students' architectural education and their perspectives on architecture in the future. As such, the article aims to paint an understanding of how multidimensional haptic learning in architecture can provide both models/model-making and sensory experiences with physical contact, given the possibility that distance learning models will become more prevalent in the future.

\subsection{Distance Learning in Architecture}

Distance learning, which derives from the early applications of correspondence education, has come to be deployed worldwide through print-based materials and various technologies, and has started to develop on a national and international scale since the 1980s. The aim of distance learning is to "offer degree-granting programs, to battle illiteracy in developing countries, to provide training opportunities for economic growth, and to offer curriculum enrichment in non-traditional educational settings" (Gunawardena and McIsaac, 2004, p. 356).

As Riel (1993, cited in Gunawardena and McIsaac, 2004, p. 356) has stated, previously, in distance learning that contained collaborative features, students from different parts of the world participated in cooperative learning activities by sharing information over computer networks. "Global classrooms," which featured different participants from different countries interacting with each other from a distance, were also "collaborative, authentic, situated learning activities" (Gunawardena and McIsaac, 2004, p. 356). Thanks to the existing web-based multimedia and information technologies at our disposal, such programs have created unity by eliminating the boundaries of "time and place" 
for distance learning (Gunawardena and McIsaac, 2004, p. 356).

In architecture schools, and especially in design studios, face-to-face education and distance education practices and environments where studio instructors and students can work independently and remotely have been maintained for the last twenty years (Masdéu and Fuses, 2017, p. 11). The University of Universities (UOU) Project, which emerged before the pandemic for Erasmus exchange students, can be cited as an example of such an ongoing online education program, providing in-studio training under the direction of Javier Sánchez Merina and Joaquín Alvado Bañón. During the pandemic, interviews supported by various collective workshops and weekly online meetings were held to bring international students together and increase studio collectivity. This has helped to expand the physical boundaries of universities and the classroom by bringing together international students and guest lecturers from around the world with different research interests (URL-1, 2020).

Distance learning has both positive and negative pedagogical aspects, both in the prepandemic phase and during the pandemic proper. Firstly, architecture and design by their very nature are collaborative, conducted within dynamic atmospheres in which there is a mutual knowledge and transferal of experience from the instructors to the students and between the students themselves as well. Physical experience-observing and feeling the real-life boundaries of studio spaces and the hands-on ways of engaging with and learning about architecture both in and out of the studio-is important for a student. Secondly, grasping the studio environment or physical sites collectively through physical touch-whether it is on an open field, in an urban context, or inside a building - enables students to perceive and observe the dynamics of those spaces through their own bodily occupation of the latter.

Much research has been conducted during the pandemic with regard to the latter's implication on architectural education. According to a cross-sectional survey conducted by Koh and Khuan Wong (2021) with 716 design, architecture, and engineering students, "the perception of online learning and its institution's engagement" during the pandemic has shown that "the pandemic has a minor effect on their university plan, where $84 \%$ are keen to re-enroll for the term and only $6 \%$ prefer to wait out the pandemic". Additionally, there is a challenge in fulfilling the educational needs of design and architecture students (Koh and Khuan Wong, 2021, p. 636). However, contrary to Koh and Khuan Wong's argument, the education within an architectural studio in particular entails a pedagogical and experiential process that is developed together by both the student and instructor - and this does not depend on a strict learning-based axis. The discovery of ambiguous and tacit knowledge by the architect is also very important in these mutually-evolving models of cognition. Another piece of research focusing on emergency remote teaching (ERT) and its effects on architectural education in the "prepandemic, during the pandemic and postpandemic stages" in Oman has shown that the "rate of interaction between student-teacher" in synchronous and asynchronous remote teaching was observed to have been reduced during the pandemic (Kauser, 2021, pp. 8990). That said, despite the quick adaptation to the emergency situation by teachers and students, the online atmosphere's pedagogical effectiveness has been reduced, as there is a diverse set of students with diverse responses and needs (Kauser, 2021, pp. 89-90).

However, most of these studies do not refer much to the perception of architecture through the human body, nor to the ability of firstgrade design students to sense both the built environment and materials, as these students are mostly unaware of such sensations and experiences. Therefore, this article focuses on the evaluation of first-grade architecture students. Since the pandemic, not many studies have focused on hapticity in distance learning in the architecture and design educational domain, but considering these remote learning 
models - which will become more widespread in the future - it is inevitable that the effects of this model in the fields of architecture and design will be discussed.

\subsection{Haptic Perception in Architectural Education}

\subsubsection{Haptic Perception}

Hapticity concerns the sense of touch. As Piaget mentions, haptic perception is developed in the early stages of childhood, with our "tactile-kin[a]esthetic impressions" crystallizing into a "spatial image of a visual kind" (Mallgrave, 2010, p. 188). The ecological psychologist James J. Gibson has asserted that our haptic system transforms information derived from objects into three dimensions (Mallgrave, 2010, p. 188). As Mallgrave explains, hapticity can be used as a "synonym for the emotive and multisensory experience of architecture, which includes the visual dimension" (Mallgrave, 2010, p. 189). Hapticity enables us to learn about surfaces and textures, as well as the sense of touch, alongside the sense of sight. Depending on the hardness, softness, roughness, inclination, or degree of horizontality of a floor, human beings are always considered to be interacting with surfaces while standing and walking. Similarly, the ability to grasp an object's properties such as its weight and surface lies behind our need to touch objects. This perception of space closely affects our spatial qualities as well as our understanding thereof (Altan, 2012, p. 85).

Similarly, Juhani Pallasmaa, in his book The Eyes of the Skin mentions that there is a close relationship between the "tactile sense for our experience and understanding of the world" as well as "between the dominant sense of vision and the suppressed sense modality of touch" (Pallasmaa, 2005, p.10). He notes that touch, as a sensory tool, "integrates our experience of the world with that of ourselves", fusing itself together with visual perception (Pallasmaa, 2005, p. 11). Pallasmaa defines hapticity and tactile experience as "multi-sensory"-an experience in which "qualities of space, matter and scale are measured equally by the eye, ear, nose, skin, tongue, skeleton and muscle"
(Pallasmaa, 2005, p. 41). He argues that "the sense of sight may incorporate, and even reinforce, other sense modalities; the unconscious tactile ingredient in vision is particularly important and strongly present in historical architecture, but badly neglected in the architecture of our time" (Pallasmaa, 2005, p. 26).

Another issue regarding haptic perception has been raised by psychologist Howard Gardner's approach (1983) to multiple intelligences in his book Frames of Mind: The Theory of Multiple Intelligences. In this book, he refers to the "spatial, bodily-kin[a]esthetic, musical, interpersonal, and intrapersonal intelligences" as examples of human cognitive capacities (Gardner, 2011, p. xii). According to Gardner, the body is:

"more than simply another machine, indistinguishable from the artificial objects of the world. It is also the vessel of the individual's sense of self, his most personal feelings, and aspirations, as well as that entity to which others respond in a special way because of their uniquely human qualities" (Gardner, 2011, p. 249).

Thanks to the work of Pallasmaa and others, the role of the body as an interface in comprehending the world and the spaces around us, as well as our kinaesthetic perceptions and sense for the environment, have begun to be discussed in architecture and compared to other perceptions. Today, the interaction of architecture with human physiology is handled with more depth and more focus on interdisciplinary interaction with other fields such as neuroscience, orthopedics, and cognitive psychology. One of the important concepts and fields of perception in this subject is kinaesthetic perception, which is also related to the haptic sense.

However, kinaesthetic learning is one of the least evaluated issues in architectural design studios. It refers to "experience by doing" through bodily sensation. The term kinaesthetic defines the "spatio-temporal continuity of the urban space" in acquiring real life experience through bodily activities such 
as walking and constructing movement (Andjelkovic, 2020, p. 28). In this respect, kinaesthetic perception-in realizing the performative realities and potentials of architectural space-transforms the spaces we live in and offers a differentiating aspect to our approach towards design.

\subsubsection{The Role of Hapticity in Architectural Design Studio}

In the past, during the Bauhaus period, basic design courses such as the Vorkurs; meanwhile, Johannes Itten and Laszlo Moholy-Nagy were also carrying out many experiments in architecture and design education to increase the motor skills and for the activation of the visual, tactile, kinaesthetic senses. These ranged from using the tactile boards of visually-impaired individuals to experiments conducted in space to ribbons and furniture proposed by one of the futurists, F. T. Marinetti, to enhance the tactile senses (Moholy-Nagy, 1947, p. 24). In the wake of the widespread and long-term training methods of the Bauhaus movement, how can we digitalize haptic education models, especially in the future, from a familiar methodology that does not merely reflect a trend or fad of the times, all while stimulating all of the senses?

In his book The New Vision, Abstract of an Artist, Moholy-Nagy mentions that

"a human being is developed by crystallization of the whole of his experience... Instead of extending our realm of action, as the primitive man was forced to do, since he combined in one person hunter, craftsman, builder, and physician, we concern ourselves with a single specific vocation, leaving other capacities unused" (Moholy-Nagy, 1947, p. 14).

In the Bauhaus education, "the powers hidden in each individual originated in a free collective structure. The pattern of a student community was developed by students who learned 'for life, not for school', which meant 'practicing real life'." The first-year education was particularly important to the movement, and therefore, "sensory experiences, toward the enrichment of emotional values and toward the development of thought," gained much importance (Moholy-Nagy, 1947, p. 19). Sensorial training focused on increasing the sense of touch and tactile perception through exercises performed using various materials, tactile tables, and surfaces. The training also included an intense psychological study of the material with the help of tactile tables, and exercises such as surface treatments played an important role as well (Moholy-Nagy, 1947, p. 23).

As for Lakoff and Johnson, the studies are related to "embodied interaction"-in which the environment, mind, and body operate together due to the neural mechanism through which sensorial and movement-based experiences intertwine (Nanda and Solovyova, 2005 , p. 155). Similarly, the act of touch, haptic experience, and the "sensations, influence, materiality and mental associations" associated with it appear not as abstract concepts, but as ideas that can be utilized in architectural design processes when we regain awareness of their complex functionalities (Öktem Erkartal and Ökem, 2015, p. 92).

In today's architectural design studios, computers play an important role both in the design conceptualization phase and in the design development, from design to modeling to animations. Architects transform their thoughts, sketches, freehand sketches, technical drawings, models, texts, and data into a design of a building and its environment. As Sheil explains, "among the host of critical and diverse traits required in architectural production, the making of buildings demands an expertise that is familiar with the tactile and the physical" (Sheil, 2005, p. 6). However, as Pallasmaa argues, "computer imaging tends to flatten our magnificent, multi-sensory, simultaneous and synchronic capacities of imagination by turning the design process into a passive visual manipulation, a retinal journey" (Pallasmaa, 2005, p. 12). Pallasmaa's definition allows us to rethink our practices within studio settings: can architecture students, especially freshmen, develop spatial- 
bodily, kinaesthetic intelligence through physicality - and mainly, through their hands? For Pallasmaa, the design process, as a "mental transfer" from the representations of drawings to the physical and material reality of the project idea and "the images with which the designer advances are not mere visual renderings; they constitute a fully haptic and multi-sensory reality of imagination" (Pallasmaa, 2009, p. 59). Model-making enables an architecture student to design, think, perceive and understand the different layers of a design problem, such as scaling and mapping, by testing the invisible data observed in a field into visible potential by testing their ideas. In other words, the architectural model as a tool enables "understand[ing], defin[ing] and measur[ing] various issues" (Smith, 2004, p. xxi).

On the other hand, simulations play an important role in increasing design-oriented thinking and the designer's ability to understand reality (Sorvig, 2005, p. 98), while on-screen methods have the advantage of showing students how buildings are constructed more easily and are more affordable compared to field trips (Sorvig, 2005, p. 104). However, perceiving reality as a presentation cannot provide a real sense of feel due to the barriers between the screen and the perceiver. While hand-drawn sketches and designs can provide a faster and more flexible approach to creativity, using electronic simulations as a design tool provides a slower and "more analytical frame of mind, which can stiffen and abstract the designer's thinking at a point when flexibility and embodiment is called for" (Sorvig, 2005, p. 98). Spiridonidis and Voyatzaki have drawn attention to the important fact that an architectural education largely depends on "proven," "tested," "predictable," "rational," and "confirmed" value systems; as such, many architectural institutions are highly "skeptical" of and "often resistant [to] the new, the unknown, the changing"- an attitude that has persisted over the past fifty years (Spiridonidis and Voyatzaki, 2010, p. 15).

\section{Material and Methods 2.1. Research Problems}

This study explores the problem that haptic learning styles risk drifting away from the holistic nature of architecture because haptic perception is less accessible to both students and instructors in distance learning. If distance education models become more widespread in the future, to what extent will this perception be affected when making models and learning about, understanding, and discussing architecture? One of the most fundamental disadvantages of the pandemic with regard to the architectural discipline is that the activity of design creates an important interface for exploring the human body when capturing ambiguous information through architecturesuch as observation, touch, perception, or ambulation. In this context, if these educational models continue over the long term in the future, how the distance education model will shape both the intellectual as well as applied practices of physicality, haptic learning, and discovery in architecture becomes an important problem that warrants discussion.

\subsection{Methods and Research Questions}

To address these problems that have arisen in distance education during the pandemic - and which may indeed continue in the postpandemic future - the perceptions of first-year students at Istanbul Aydin University's Department of Architecture on this topic were registered through in-depth interviews recorded via Zoom.

Unlike face-to-face education-where one's body and limbs can move-distance education has increased the workload of instructors, as architectural studio hours are conducted by sitting in front of the screen for a long time. Beyond the students' experiences, the pandemic has also had consequences on architecture instructors' usual channels of imparting knowledge. This can cause not only mental stress and fatigue but also various physical health impairments, especially in situations where vision, hearing, and hands are used extensively. In other words, distance education may result in inadequate 
communication or an inability to communicate effectively in an online architectural studio, as it restricts bodily mobility. For this purpose, the authors of this study, who did not meet face-to-face before the research process, also had the opportunity to meet for the first time over Zoom. However, to minimize the loss of time by writing out all of the discussions by hand, voice-conversion applications on mobile phones and Google Drive, for example, were used to convert their meetings and interviews to text. Since this method requires less handwork, it has proved convenient in writing the article.

In the interviews, meanwhile, nine questions were asked to investigate the haptic perceptions of the students. These questions were mainly designed to examine students' understanding of experiencing materiality, to articulate the difficulties they observed in doing so in their virtual studio time during the pandemic, and to understand how effectively students use their hands and bodies. Since the students did not yet have a wide perspective in comprehending the holistic nature of architecture, they tried to comprehend materials with which they came into direct physical contact. At the same time, sports, crafts, and other activities which increase the haptic experiences of the students have also been recorded.

Students' relationships with the materials were based on the context of "material encounter" and "material engagement" proposed by Karana et al and based on Henri Focillon (1992) and John Dewey (1980) (Karana et al., 2015, p. 38). The foundations of this approach were actually laid in the Bauhaus period, with the approaches of Bauhaus instructors such as Itten and Moholy-Nagy, which stressed the role and value of sensory encounters and the importance of "hands-on manipulation in material understanding" (Karana et al., 2015, p. 38).

\subsection{Participants and the Study Setting}

At Istanbul Aydin University, which has a four-year architecture degree, students in the first year of their architectural education take the following courses: "Introduction to Architectural Design I-II", "Fundamentals of Visual Design", and "Communication Media III". They also take "Fundamentals of Architectural Design I-II" and "Construction Technology I-II". During the pandemic, students attended face-to-face courses in the department, where the number of people and the duration of the lessons were adapted within the framework of the "hybrid education" model in both periods. Of these courses, the "Introduction to Architectural Design I-II" studio course, which had been required eight hours a week before the pandemic, was reduced to four hours a week over Zoom after the outbreak of Covid-19. The content of the course includes the form, characteristics, and transformation methods as well as the horizontal and vertical elements that define space; it also explores the openings within these elements concerning the relationship between form and space, spatial organizations, and principles of spatial arrangement. Within the scope of "Introduction to Architectural Design I-II," students design a three-story housing project-which includes the lower, upper, side shells, and structural elements of the architectural structure-under the supervision of the group instructor throughout the semester. Secondly, they also design projects by producing original architectural programs on selected subjects from certain fields, such as science, arts, sports, etc.

To understand how distance education has affected architectural students, in-depth interviews were conducted during the second semester with a total of 20 randomly chosen first-year students (out of a total of 41 in the program) aged between $18-24$. $50 \%$ of the students were female and $50 \%$ were male. First-year architecture students who participated in the in-depth interviews on the courses determined by the appointment system (within the scope of their hybrid education) attended practical lessons in groups of three with their instructors. In the first semester, face-to-face classes were held for the first six weeks by appointment, while the following nine weeks entailed distance learning. In the second semester, the students continued their 
online education for the first three weeks, a face-to-face education for two weeks, and then online courses again for the remainder of the semester. The students answered the questions based on their distance education experiences in both semesters. Students were contacted by phone and invited to participate in the in-depth interviews online through Zoom. Interviews with the students were made in 20-40-minute time intervals and the interviews took place over two complete days within a one-week interval.

\section{Research Results}

In the past, based on the Bauhaus pedagogy and the observations of Merleau-Ponty and Pallasmaa on how design triggers haptic and sensorial perceptions, questions in the interviews were asked based on students' material experiences. This research managed to determine that all of the students participating in the interviews live in urbanized areas and that $85 \%$ of them have experienced the construction of at least some kind of building. In the buildings designed by the students, when reflecting upon both semesters in their architectural education before the formation of their theoretical foundations, the "place of experienced materials" was determined as the dominant factor, at $60 \%$. Students were asked about the way in which they perceive the space through the materials, and by seeing (optical) the materials, they all suggested that their designs before and during the process entailed $85 \%$ touching, $5 \%$ tasting, $40 \%$ smell, $30 \%$ hearing, $35 \%$ bodily sensation (kinaesthetic), while 5\% experienced the materials physically. $80 \%$ of the students have used these materials in their construction sites, while $45 \%$ have seen them in a construction store, $10 \%$ as a display product in a construction fair or a material exhibition, $35 \%$ through the studio instructor. $70 \%$ have encountered the materials in their living environment, while $70 \%$ have also seen the representation of the material in two dimensions (in the form of a plan, section,

elevation, or perspective) in printed or digital media (books, magazines, building catalogs, brochures, etc.). $30 \%$ have seen an image of the material but only its technical properties (size, thickness, etc.) in printed or digital media, while $45 \%$ have seen a representation of the material through animations, videos, or documentaries on the internet. The ratio of people engaged in sports and art activities as non-architectural activities is high (40\%); $80 \%$ of those had seen the construction technique of reinforced concrete structures. Meanwhile, the perception of materials using only the optic senses is low (10\%), 40\% have experienced the materials in the home environment and the printed or digital environment, while $35 \%$ have done likewise through their studio instructor and printed or digital media (35\%). The percentage of those who work in the studio by sketching using their hands or a digital pen and with various drawing or design programs on the computer (or using other digital tools) is high $(40 \%)$. Issues related to educational obstacles include time efficiency, a failure to experience the design process with the coordinator, and communication problems with the instructor $(40 \%)$. It has been determined that during the pandemic period, $85 \%$ of students would prefer to work with a pen on paper or through hand drawing as well as design in computer-based digital environments as such design methods enable them to see their education as hybrid or prepare them for a completely digital future (Table 1). 
Table 1. Data and evaluation of answers of participants

\begin{tabular}{|c|c|c|}
\hline & Frequency & $(\%)$ \\
\hline \multicolumn{3}{|l|}{ Interests } \\
\hline None & 2 & 10 \\
\hline Sports only (football, basketball, fitness, boxing) & 3 & 15 \\
\hline Sports and handcrafts & 1 & 5 \\
\hline Drawing & 3 & 15 \\
\hline Art only & 3 & 15 \\
\hline Sports and art & 8 & 40 \\
\hline \multicolumn{3}{|l|}{ Observed Construction Techniques } \\
\hline Industrialized Techniques (Reinforced Concrete) & 16 & 80 \\
\hline Industrialized Techniques (Steel Construction) & 2 & 10 \\
\hline Industrialized Techniques + Masonry & 1 & 5 \\
\hline None & 1 & 5 \\
\hline \multicolumn{3}{|l|}{ Factors affecting students' design material selection in architectural studio } \\
\hline Experiencing material face-to-face + its technical features & 7 & 35 \\
\hline $\begin{array}{l}\text { Architectural studio environment }+ \text { researching material in catalogs/digital } \\
\text { environments }\end{array}$ & 6 & 30 \\
\hline Architectural studio environment only & 7 & 35 \\
\hline \multicolumn{3}{|l|}{ Perceiving materials } \\
\hline Optic only & 2 & 10 \\
\hline Optic + haptic & 8 & 40 \\
\hline Optic + haptic + taste + olfactory + auditory & 10 & 50 \\
\hline \multicolumn{3}{|l|}{ Place of experienced materials } \\
\hline Construction Environment (Construction site + Construction market/ fair) & 3 & 15 \\
\hline Non-face-to-face (Representation in a printed/digital media) & 2 & 10 \\
\hline Home environment + Non-face-to-face (Representation in a printed/digital media) & 8 & 40 \\
\hline $\begin{array}{l}\text { Home environment }+ \text { Instructor of the studio }+ \text { Non-face-to-face (Representation } \\
\text { in a printed/digital media) }\end{array}$ & 7 & 35 \\
\hline \multicolumn{3}{|l|}{ Methods for sharing students' design with studio instructor } \\
\hline $\begin{array}{l}\text { Free-Hand drawing/ taking photos/ scanning }+ \text { Developing design with digital } \\
\text { tools }+ \text { designing with digital tools }\end{array}$ & 2 & 10 \\
\hline
\end{tabular}




\begin{tabular}{|c|c|c|}
\hline $\begin{array}{l}\text { Free-Hand drawing/ taking photos/ scanning }+ \text { Free-Hand drawing/ developing } \\
\text { design with digital tools }+ \text { designing with digital tools }\end{array}$ & 5 & 25 \\
\hline $\begin{array}{l}\text { Free-Hand Drawing with/without digital pen and developing design with digital } \\
\text { tools }\end{array}$ & 8 & 40 \\
\hline $\begin{array}{l}\text { Free-Hand drawing/ taking photos/ scanning }+ \text { Free-Hand Drawing with/without } \\
\text { digital pen and developing design with digital tools }+ \text { Developing design with } \\
\text { digital tools }\end{array}$ & 5 & 25 \\
\hline \multicolumn{3}{|l|}{$\begin{array}{l}\text { Educational/Communicational obstacles in architectural design studio during } \\
\text { pandemics }\end{array}$} \\
\hline Technological problems (Communicational problems) & 1 & 5 \\
\hline Access to model making materials & 2 & 10 \\
\hline $\begin{array}{l}\text { Design efficiency in digital environment (time inefficiency, communication } \\
\text { problems with instructor) }\end{array}$ & 8 & 40 \\
\hline $\begin{array}{l}\text { Decreased interaction (communication problems with classmates, inability to } \\
\text { expression of the students) }\end{array}$ & 7 & 35 \\
\hline None & 2 & 10 \\
\hline \multicolumn{3}{|l|}{ Future expectations for the students in architectural design studio } \\
\hline Hand drawing/design + physical model & 1 & 5 \\
\hline Design/Modelling with digital tools & 2 & 10 \\
\hline Hand drawing/design + design with digital tools & 17 & 85 \\
\hline \multicolumn{3}{|l|}{ Model making } \\
\hline None & 1 & 5 \\
\hline Design with digital tools only & 5 & 25 \\
\hline Physical model only & 6 & 30 \\
\hline Design with digital tools + Physical model & 2 & 10 \\
\hline $3 \mathrm{D}$ printer & 4 & 20 \\
\hline Design with digital tools $+3 \mathrm{D}$ printer & 1 & 5 \\
\hline Physical model + Design with digital tools $+3 \mathrm{D}$ printer & 1 & 5 \\
\hline
\end{tabular}

The technological and online environment of those who do not have original features other than studying architecture is as follows: only those who do sports or are engaged in handcrafts lacked access to materials and interaction; those who draw lacked online educational experience; when only concerning the online environment, those who are interested in art demonstrated a low interaction rate. Hence, it has been determined that those who work with sports and arts have problems with the online environment and a lack of interaction. It was seen that the students who stated that there was no difference in education before and after the pandemic were among those who only deal with art, sports, and sports as well as art (Table 2). 
Table 2. Interests and educational/ communicational obstacles in the architectural design studio during the pandemic

\begin{tabular}{|l|l|l|l|l|l|}
\hline Interests & $\begin{array}{l}\text { Technological } \\
\text { problems } \\
\text { (communicational } \\
\text { problems) }\end{array}$ & $\begin{array}{l}\text { Access to } \\
\text { materials }\end{array}$ & $\begin{array}{l}\text { Design efficiency in } \\
\text { digital environment } \\
\text { (time inefficiency, } \\
\text { communication } \\
\text { problems with } \\
\text { instructor) }\end{array}$ & $\begin{array}{l}\text { Decreased } \\
\text { interaction } \\
\text { (communication } \\
\text { problems with } \\
\text { classmates, } \\
\text { inability to } \\
\text { expression of the } \\
\text { students) }\end{array}$ & None \\
\hline None & 1 & 0 & 1 & 0 & 0 \\
\hline Sports only & 0 & 1 & 0 & 2 & 0 \\
\hline Sports and crafts & 0 & 1 & 0 & 0 & 0 \\
\hline Drawing & 0 & 0 & 3 & 0 & 0 \\
\hline Art only & 0 & 0 & 2 & 1 & 2 \\
\hline $\begin{array}{l}\text { Sports, music and } \\
\text { performing art }\end{array}$ & 0 & 0 & 2 & 4 & \\
\hline P=0.042<0.05 significance level & & & & \\
\hline
\end{tabular}

A close relationship has been found between "observed construction techniques and perceiving materials". It has been found out that students have more commonly experienced reinforced concrete and steelindustrial construction techniques where the hand is used less than observed construction techniques - than traditional masonry systems, since all of the students noted that they live in urbanized cities. The ways in which students can perceive these production processes and materials were determined as optic, haptic, gustatory, olfactory, and auditory, respectively (Table 3). 
Table 3. Observed Construction Techniques and Perceiving materials

\begin{tabular}{|l|c|c|c|}
\hline & Optic only & Optic + haptic & $\begin{array}{r}\text { Optic + haptic + } \\
\text { taste + olfactory + } \\
\text { auditory }\end{array}$ \\
Techniques & & & 8 \\
\hline $\begin{array}{l}\text { Industrialized Techniques } \\
\text { (Reinforced Concrete) }\end{array}$ & 1 & 7 & 2 \\
\hline $\begin{array}{l}\text { Industrialized Techniques } \\
\text { (Steel Construction) }\end{array}$ & 0 & 0 & 0 \\
\hline $\begin{array}{l}\text { Industrialized Techniques }+ \\
\text { Masonry }\end{array}$ & 0 & 1 & 0 \\
\hline None & 1 & 0 & \\
\hline $\mathbf{P = 0 . 0 4 7 < 0 . 0 5}$ significance level & & & \\
\hline
\end{tabular}

Those who saw the reinforced concrete skeleton construction did not model digitally or make models with 3D printers, but they did use all other techniques. Meanwhile, those who saw the construction of the reinforced concrete and steel skeleton made only physical models. It was determined that those who saw reinforced concrete and steel and masonry construction had conducted some digital modeling using a $3 \mathrm{D}$ printer.

\section{Discussion}

The most common problems experienced by the students in the architectural design studio during the pandemic period are design efficiency in the digital environment, decreased interaction, the inability to express themselves, the inability to observe other students' designs in an online or hybrid context, the lack of access to model-making materials, and technological or communicational problems. During the interviews, it was revealed that students' preferences and opportunities to meet with other students outside the studio to exchange ideas emerged as an important issue. This situation created a disadvantage for the students to discuss and practice their ideas collectively in the studio environment.

Based on the research data, the approach of gaining a better understanding of the materials through touch - which is lost in contemporary digitalized architectural practices - is slightly decreasing. In the in-depth interviews, it was revealed that the students mostly prefer to design and draw in a computer environment, which is also very common in the face-to-face education environment. Similarly, in the applications performed with students in architectural design studios, students who do not partake in a hobby, handicraft, or bodilyengaging activity such as sports or dance demonstrated less interest in making models by hand and sketching with a pencil or digital pen. Even though the relationships between the students' interests were not deemed significant according to the study's statistical data, the students who display an interest and/or engage in the aforementioned fields of sport, music, or performance arts placed more importance on the haptic senses in their architectural design 
studio courses. It was also revealed that the visual was more predominant than the haptic (or other senses) in the students' perception of the built environment, and that they lacked knowledge about, experience with, and an awareness of the other senses (Table 3). This situation emphasizes the holistic approach of sensory experimentation-widely used in Bauhaus education - and the need for developing transformative design environments through today's developing technologies and perspectives. Another issue in distance education is the limited opportunity for transfer between students of their respective haptic experiences. In this context, forms of architectural representation may mask the acquisition of knowledge and experience when touching nature and sensing the environment. It was determined that students who had experienced industrial techniques thought to use other techniques than designing with digital tools or 3D printers in the architectural studio course. Meanwhile, students who had not witnessed any production technique prefer to physically produce firstly using 3D printers, and thereafter, with digital tools and physical models, depending on their need to see and touch their designs in 3D.

In relation to the variety of construction techniques that the students had witnessed, a tendency to prefer 3D physical productions has been observed among the design and modeling methods that they are likely to prefer in future architectural studio courses. Additionally, the students predominantly prefer to continue their development using free-hand drawing and digital tools. The study showed that they have chosen to continue the design methods that were predominantly being used before the pandemic at the university. Similarly, this situation overlaps with the way in which students design in the studio environment and share with the executive during the pandemic period. Figure 1 shows the key concepts that the students verbally identified and are likely to prefer in their future studio environments.

As seen in Figure 1, some such concepts include: "free-hand design efficiency", "experiencing free-hand design pleasure", "design genuineness on paper", "free from digital constraints", "self-reliance provided by model-making", "thinking with hands", "courage to sense with touch", "rapidity in the design process", "comprehending scale in design", "providing different perspectives in the digital atmosphere", "restrictions to flexibility in a digital design atmosphere."

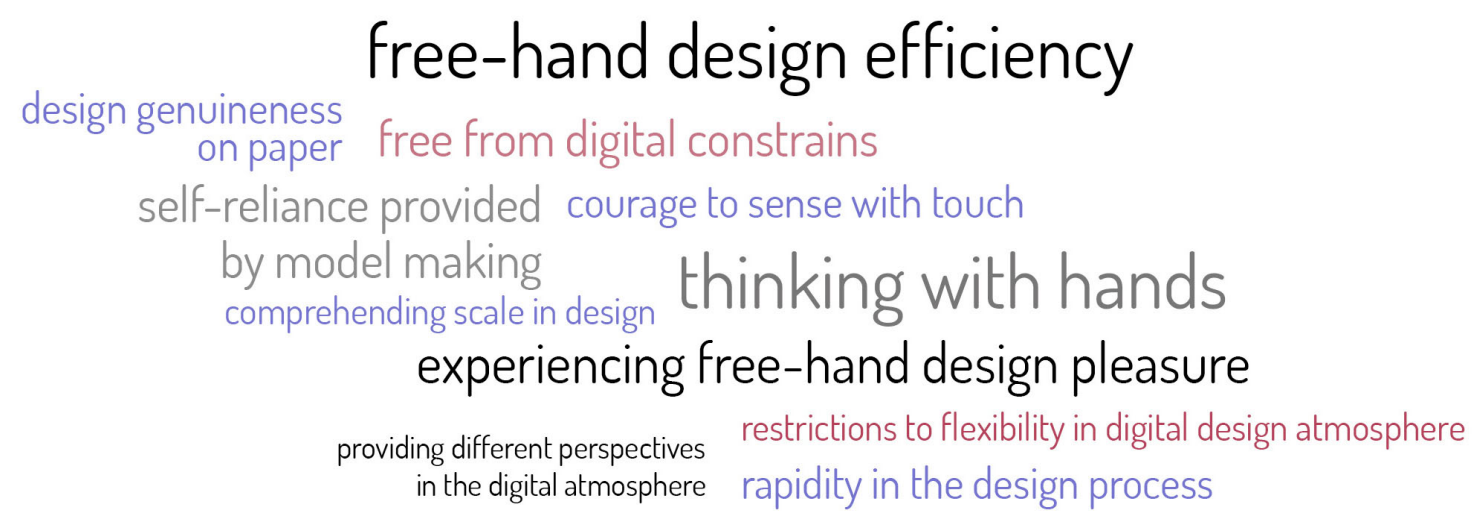

Figure 1. Emerging concepts in the preferences of students in architectural studio environments for the post-pandemic period 
In "factors affecting students' design material selection" in the studio, the students preferred materials that they had seen and experienced before in their designs; this also held true when researching their technical properties - that is, they mainly preferred materials whose physical and technical features they had seen. The latter they had either witnessed in the architectural studio or had selected based on the information conveyed to them by the director. The students' choice after seeing a representation of the material was relatively less influential in their decisions.

It is evident that in the "place of experienced materials", students have seen representations of the materials in print or digital media or have experienced and found them in environments such as their home and neighborhood. However, at this point, it was not observed that students take an experimental approach to discover or design new materials that have not yet been produced or observed. Consequently, one can conclude that construction sites and building fairs-in addition to the studio environment-are important in increasing haptic experimentation in terms of both the selection of existing materials and the production of new ones. In this way, the haptic experience that students will gain by encountering different materials will be able to develop their holistic design perspective.

It could be claimed that this increases the ability of the student to increase their creativity and transforms the possibilities available through traditional design methods; however, on the other hand, the ability to think with one's hands has been limited in the digital environment and for architectural students who can make model models or robotic designs on very limited scales. It can be argued that designing productions using digital representations creates some experiential weaknesses in understanding the hapticity of materials.

The visual documentation and representation of a design-increased by digital communication - will cause the role of haptic elements in the design to transform from an instructive or imaginative and contemplative state to an interior element of the design itself. The disappearance of the physical or haptic properties of the material will trigger a different perception. For example, in a situation where computer keyboards are eliminated and instead reflected on the table with infrared rays, drawing on the table or space may fulfill our desire to physically touch it while designing without a computer, keyboard, or mouse. Working with infrared or touchscreens can be restrictive for the experienced designer and risks confusing the brain's multi-faceted activities. When this is considered inevitable, it is obvious that we need new paradigms. In fact, the digital world is already an inseparable, indispensable interface for the architectural education of today.

These approaches - whether kinaesthetic or relating to spatial perception - are experienced by students who are relatively more advanced on an individual level; indeed, it can be said that they provide benefits for students who are far from the directives or help of a guide, and, on the other hand, who can independently pose problems and develop solutions to them. However, it can be argued that distance education may not yield the same expressions and results in an architectural environment. It would not be wrong to say that the internal dynamics of an education in design would be negatively affected should digital education methods become more widespread in the future.

\section{Haptic Perception in Distance Education}

As Coffield, Moseley, Hall, and Ecclestone (2004, cited in Hamza-Lup and Stanescu, 2010 , p. 79) have noted, considering that about $15 \%$ of the population learns kinaesthetically, this latter group has difficulties in trying to grasp concepts fully by just reading or listening. In the absence of haptic channels, the quality and quantity of information transmitted through an interface and the efficiency of the learning and comprehension process both decrease. Particularly in distance learning, the absence of this sense, although less than other 
perceptions, does negatively affect the acquired cognitive outcomes. In this context, haptic experiences that are also being developed in the digital environment can provide a space for learning by doing, enriching the existing audiovisual environment through direct experience.

Today's advanced computer networks carry information related to both the auditory sense (e.g., sounds and speech) and the visual sense (e.g., videos, graphics, and text) — a format that is common today. Embedding haptic feedback into these networks and applications and distributing them over the internet, activating other senses in so doing, will create the potential to solve the existing bottlenecks in distance learning (Hamza-Lup, and Stanescu, 2010, p. 79). In the case that distance learning becomes widespread in architecture and design studios, such digital haptic applications can gain importance in terms of providing an experience for the students' sensorial awareness, even if the latter is limited to haptic experience.

\section{Conclusion}

As some of the students have stated, the virtual tours that they take online-intended to serve as representations of the environments they work in-create a restrictive framework compared to perceiving and observing architecture on-site, in turn affecting their ability to develop flexible approaches to design. Current technologies such as virtual reality and augmented reality have the potential to radically alter perceptions and perspectives on architecture. However, the direct multi-modal experience of the physical environment brings a deeper, more effective understanding of the world than these technologies. Understanding architecture only through the digital representations of the physical world and "representing" appears as an altering factor in a holistic architectural perspective. Architectural education and design studios built on a representative world also create a mechanical, reduced, overdesigned, and over-engineered world in this context.
The prospective designer who is formed in a fully digitalized context may hence stay away from real-life experiences of architecture. The designer may as such produce perceptual losses in the haptic and olfactory realms, as their perception moves away from the multidimensional integrity of the mobile world toward the digital world. In this case, do digital screens turn into a monotypic design perspective that takes place in the form of more rational prototyping, in the form of shortcut problems for designers, developing solutions without understanding the atmospheric character of the spaces?

Within the scope of the haptic methodology of design and neuroarchitecture today, the role of haptic perception within the pedagogy of the architecture studio should be reconsidered and engaged within changing educational frameworks. It is a fact that digital education will gain even more importance in the future, despite the fact that designers have been advocating for the priority of the sense of touch for years, at every opportunity. The results of this study also support the importance of the sense of touch. Perhaps in the future, we will encounter more digital haptics in architecture and design education. However, evaluating hapticity and its perception through measuring or comparing the role hereof is also the subject of another study.

\section{Acknowledgments:}

This research was approved by the Istanbul Aydin University Social and Human Sciences Ethical Committee (approval number: 2021/533). All the authors were involved at every stage of the study. We would like to thank all the students who contributed their valuable insights to our article.

\section{References:}

Altan, İ. (2012). Mimarlikta Mekan Kavramı. Psikoloji Çalışmaları, 19 (0), 75-88. Retrieved from

https://dergipark.org.tr/tr/pub/iupcd/issue/9414 $/ 118010$. 
Andjelkovic, K. (2020). Kinesthetic Imagination in Architecture: Design and Representation of Space. Život umjetnosti, 106 (1), 22-35. doi: 10.31664/zu.2020.106.02.

Hamza-Lup, F. G., and Stanescu, I. A. (2010). The Haptic Paradigm in Education: Challenges and Case Studies. Internet and Higher Education, 13 (1-2), 78-81. doi: 10.1016/j.iheduc.2009.12.004.

Gardner, H. (2011). Frames of Mind, The Theory of Multiple Intelligences. New York: Basic Books.

Gunawardena, C. N., and McIsaac, M. S. (2004). Distance Education. In D. Jonassen (Ed.), Handbook of Research for Educational Communications and Technology (2nd ed.), 355-395. Association for Educational Communications \& Technology. Mahwah, NJ: Lawrence Erlbaum.

Ibrahim, A. F., Attia, A.S., Bataineh, A' M., and Ali, H. A. (2020). Evaluation of the Online Teaching of Architectural Design and Basic Design Courses Case Study: College of Architecture at JUST, Jordan. Ain Shams Engineering Journal, 1-9. doi: 10.1016/j.asej.2020.10.006 .

Karana, E., Barati, B., Rognoli, V., and van der Laan, A. Z. (2015). Material Driven Design (MDD): A Method to Design for Material Experiences. International Journal of Design, 9 (2), 35-54.

Kauser, N. (2021). Rethinking Architecture Pedagogy in The Era of Pandemics. STHALA, 1, 84-91. Retrieved from https://sjbsap.edu.in/wpcontent/uploads/2021/01/file-14Sthala_VOL_1_Jan_21.pdf.

Koh, P. C. L., and Khuan Wong, S. (2021). Students' Perception of Online Learning and Institution's Engagement During the Covid-19 Pandemic: A Survey Study of Taylor's Design, Architecture and Engineering Students. Journal of Engineering Science and Technology, 16 (1), 635- 651. Retrieved from
http://jestec.taylors.edu.my/Vol\%2016\%20issu e\%201\%20February\%202021/16_1_44.pdf.

Mallgrave, H. F. (2010). The Architect's Brain: Neuroscience, Creativity, and Architecture. Oxford: Wiley-Blackwell.

Masdéu, M., and Fuses, J. (2017). Reconceptualizing The Design Studio in Architectural Education: Distance Learning and Blended Learning as Transformation Factors, Archnet-IJAR: International Journal of Architectural Research, 11 (2), 6-23.

Moholy-Nagy, L. (1947). The New Vision, Abstract of an Artist. New York: Wittenborn, Schultz, Inc., 4th revised edition (originally published in 1928).

Nanda, U., and Solovyova, I. (2005). The Embodiment of the Eye in Architectural Education. In E. Harder (Ed.), Writings in Architectural Education, EAAE Prize 20032005, Transaction on Architectural Education, 26 (150-161). Copenhagen: From \& co.

Öktem Erkartal, P., and Ökem, H. S. (2015). Mimari Tasarımda Dokunma Olgusu ve Dokunsal Haritalamaya İlişkin Bir Alan Çalışması. Megaron, 10 (1), 92-111. doi: 10.5505/MEGARON.2015.30602.

Pallasmaa, J. (2009). The Thinking Hand (Existential and Embodied Wisdom in Architecture). Chichester: Wiley.

Pallasmaa, J. (2005). The Eyes of the Skin. England: John Wiley \& Sons.

Salama, A. M., and Crosbie, M. J. (2020, October 14). Educating Architects in a PostPandemic World. Common Edge. Retrieved from https://commonedge.org/educatingarchitects-in-a-post-pandemic-world/.

Sheil, B. (2005). Design Through Making: An Introduction. Architectural Design, 75 (4), 512. doi: 10.1002/ad.97. 
Smith, Albert C. (2004) Architectural Model as Machine, A New View of Models from Antiquity to the Present Day. Oxford: Architectural Press, Elsevier.

Sorvig, K. (2005). Virtual and Real: Teaching the Paradoxes of Design. In E. Harder (Ed.), Writings in Architectural Education, EAAE Prize 2003-2005, Transaction on Architectural Education 26 (85-109). Copenhagen: From \& co.

Spiridonidis, C., and Voyatzaki, M. (2010). Educating Architects Towards Innovative Architecture. EAAE Transactions on Architectural Education, 50, 13-18. Copenhagen: From \& co.

URL-1, (2020, April 12). Concept. University of Universities. Retrieved from

https://uou.ua.es/ 